\title{
A Case Study In Strategic Financial Planning In Health Service Organizations
}

Nancy J. Niles, Lander University, USA

\begin{abstract}
Integrating strategic planning and financial planning is the best way for health service organizations (HSOs) to ensure their budget allocations are appropriately targeted to long range solutions. In strategic financial planning, in order to ensure that there is long range financial success, annual budgets need to be analyzed from a long term organizational perspective. This paper will propose a step by step approach to strategic financial planning and their application to the healthcare industry and how the integration of these processes will result in a long term successful framework for achieving the HSO's mission and vision. Cleveland Clinic will be discussed as an example of an HSO that has successfully utilized strategic financial planning.
\end{abstract}

Keywords: strategic financial planning, health service organizations

\section{INTRODUCTION}

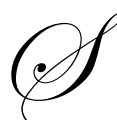

trategic planning is the action plan for running a business over a long term period. This plan is a commitment by senior management to pursue established sets of goals that are developed to promote the company's vision and mission (Thompson, Strickland \& Gamble, 2008). Financial planning is the process of analyzing the financial opportunities of the organization and selecting opportunities that will provide financial success (McLean, 2003). Integrating strategic planning and financial planning is the best way for HSOs to ensure their budget allocations are appropriately targeted to long range solutions. In strategic financial planning, in order to ensure that there is long range financial success, annual budgets need to be analyzed from a long term organizational perspective. Establishing multi year forecasting for the organization provides the financial reality that will support activities that will focus on the mission and vision of the organization. This paper will propose a step by step approach to strategic financial planning and their application to the healthcare industry and how the integration of these processes will result in a long term successful framework for achieving the HSO's mission and vision. Cleveland Clinic will be discussed as an example of a health service organization that has successfully utilized the steps in strategic financial planning.

\section{STRATEGIC PLANNING AND FINANCIAL PLANNING PROCESSES}

According to Runy (2005), the following are steps in the strategic planning goal process and the financial planning goal process:

(a) step one: establish a mission and vision statement of the organization;

(b) step two: develop a long term plan that supports the mission and vision of the organization;

(c) step three: create plans at each organizational level that integrate the mission and vision;

(d) step four: identify and evaluate the organization's external environment for new opportunities;

(e) step five: develop forecasting for market opportunities;

(f) step six: develop a plan based on capital budgets, and

(g) step seven: monitor and evaluate the results. Revise, as needed. 


\section{FINANCIAL PLANNING GOALS}

(a) step one: evaluate the current performance of the organization;

(b) step two: compare the organization's performance against historical data;

(c) step three: develop financial projections;

(d) step four: assess the organization's financial status;

(e) step five: integrate the financial goals with the strategic goals to ensure compatibility, and

(f) step six: monitor and evaluate the results. Revise, as needed.

Based on Runy's step by step process of strategic and financial planning, the following is a step by step strategic financial planning process that can be successfully utilized by a healthcare organization. Each step will be discussed individually.

\section{PROPOSED STEPS OF THE STRATEGIC FINANCIAL PLANNING PROCESS IN HSOS}

(a) step one: establish the mission and vision statement of the organization. Revise, as needed;

(b) step two: create mission and vision statements at all department levels that support the organization's mission and vision;

(c) step three: assess the current performance of the organization and compare it to historical data;

(d) step four: develop a plan based on capital budgets which support the mission and vision of the organization;

(e) step five: integrate the financial goals with the strategic goals to ensure compatibility;

(f) step six: identify and evaluate the organization's external environment for new opportunities;

(g) step seven: develop financial projections based on new opportunities. Assess the risk associated with these new opportunities;

(h) step eight: monitor and evaluate results and revise as needed.

\section{STEP BY STEP DISCUSSION}

(a) step one: Establish the mission and vision statement of the organization.

In order to have successful strategic financial planning, it is important that a mission and vision statement of the organization must be developed which is the first step of the strategic planning process. Once the mission and vision statement are established, then a long range plan, step two, must be developed to support the mission and vision statements, followed by step three, that defines the responsibilities of each department to support the organization's mission and vision. However, it is important that before a long range plan is developed and departments develop supporting goals, there must be a coordination of the finance department to develop a strategic plan based on the capital reality of the organization. A strategic plan will not be successful if there is no capital to implement the plan. There are similar steps in both the strategic and financial planning steps.

Table 1 Cleveland Clinic Mission and Vision Statement

\begin{tabular}{|l|}
\hline $\begin{array}{l}\text { The mission of Cleveland Clinic is to provide compassionate healthcare of the highest quality in a setting of education and } \\
\text { research. }\end{array}$ \\
\hline $\begin{array}{l}\text { Vision Statement and Core Values: Cleveland Clinic was established by visionary leaders who believed in five simple, guiding } \\
\text { principles: }\end{array}$ \\
\hline$\bullet \quad$ Collaboration: Patients will benefit from the collective wisdom of a team of health care professionals. \\
\hline $\begin{array}{l}\text { Quality: A commitment to quality has created the Cleveland Clinic's legacy of achievements and innovations, resulting } \\
\text { in excellent and cost-effective patient care. }\end{array}$ \\
\hline Integrity: An adherence to scientific and professional integrity is the ethical cornerstones that underlie our delivery of \\
patient care.
\end{tabular}

Source: http://www.clevelandclinic.org 
According to Longest \& Darr (2008), most healthcare organizations connect their mission statements to their vision statements with a core set of values. Their vision statements are less specific than the mission statement but do provide a strategic view of their direction. Table 1 provides an example of mission and vision statements of a prominent healthcare organization, Cleveland Clinic. This organization directly connects it mission and vision statements with core values. This example is typical of a mission and vision statement of a health service organization.

Once the mission and vision statements are established with the corresponding values, the organization at all levels can develop coordinated plans to achieve these organizational goals.

(b) step two: Create mission and vision statements at all department levels that support the organization's mission and vision.

The Cleveland Clinic also has mission statements developed for each of their major departments. Each department mission statement must support the organization's major mission statement. For example, the Board of Trustees has both a finance and investment committee. The Finance committee's mission is to provide assistance to the Board of Trustees in overseeing the financial strategies and policies of the Cleveland Clinic. Committee's mission is to provide oversight of the Cleveland Clinic's endowment and other invested assets, in order to ensure that the Clinic's long-term investment objectives are met (http://www.mycleveland.clinic.org).

\section{(c) step three: Assess the current performance of the organization and compare it to historical data.}

Prior to performing any type of financial planning, it is important to assess the state of the organization, particularly during this economic recession. In an HSO, performance assessment will consist of several indicators that reflect their mission and vision statement. Generic hospital performance indicators often examine number of patient visits, inpatient visits, number of admissions, number of emergency room visits, number of surgical cases and total operating revenues. Depending on the type of HSO, other factors will be assessed.

For example, the Cleveland Clinic's mission and vision statements focus on providing compassionate quality patient care while maintaining rigorous education and research for their employees and commitment to their communities. In their 2008 annual report, they indicate they have eight enterprise goals that focus on their mission and vision statement. The goals include putting patients first, safety and quality in their operations, growth in their core businesses and pursuit of new business opportunities, pursuit of research that improves patient care, academic excellence, community leadership and foster excellent working conditions. In their 2008 annual report, the Cleveland Clinic reported data from 2002-2007 on the generic performance indicators listed above as well as those indicators that reflect their mission, vision statements and core values. These performance indicators include number of residents and fellows, continuing medical education, accredited residency training programs, allied health students, grant revenue and philanthropy levels.

Also reflected in their mission and vision statement is the importance of being a socially responsible organization which develops and maintains a relationship with their community as well as enhancing their image. The Clinic reports that it is a major purchaser of goods and services in the Ohio area-spending $\$ 780$ million in 2006. They also employ 31,000 full-time employees. From 2004-2006, they spent $\$ 500$ million on new construction projects. They have developed community programs such as Neighbor to Neighbor which appoints a health educator to a targeted community to develop an interactive health program. The Clinic also established the Office of Civic Education commitment to promote education in partnership with area organizations to create innovative programs to enhance children's education. In 2006, the Cleveland Clinic contributed a record $\$ 1.2$ million to the United Way (State of the Clinic, 2006).

(d) step four: Develop a plan based on capital budgets which support the mission and vision of the organization.

Capital budgets are long term budgets for purchasing assets, programs, or projects that are based on the strategic plan of the organization. It is an integral component of the strategic management process. The finance 
department collaborates with senior management to integrate financial planning with strategic planning to ensure the capital budget supports their mission and vision statements. According to Mclean (2003), a capital budget must assume that the asset will pay for itself either by generating revenue or receiving funding externally. If it will not pay for itself, then the proposed asset should not be pursued. Capital budgeting decisions are also contingent on the legal structure of the HSO. Although the Cleveland Clinic is a not for profit organizations, which has goals other than investor profitability, they still need to pursue a capital budget that must assess their cash flow so it can be invested back into the organization to increase or improve services to their patients. According to Sussman (2008), a capital budget is a function of operating revenues, use of external debt, balance sheets changes and projected philanthropy levels. Philanthropy to not-for- profit organization such as the Cleveland Clinic is an integral component of their cash flows which are often noted on their balance sheets or noted as non operating revenue on their income statements.

The Cleveland Clinic has always recognized the importance of philanthropy to their organization. They have recognitions societies for donors to the Cleveland Clinic who contribute as little as $\$ 100$ to millions. They have 20 different funds that represent different diseases or research. All of their buildings are named after the benefactor. This type of marketing encourages other benefactors to donate to the Cleveland Clinic. Cleveland Clinic developed a campaign in 1995, which has a goal of raising 1.25 billion to focus on four areas: patient care, research, campus growth, and education. As of May 2009, \$1.18 billion has been raised. In 2006, an all-time high of $\$ 370$ million was donated (http://my.clevelandclinic.org). They utilize their endowments to increase their opportunities to provide patient care by building expansions, increasing the number of specialties offered, expanding geographically, etc.

Hospitals have faced scrutiny regarding their pricing of services. In 2009, a report was published in collaboration with Deloitte that exhibited a new strategic financial strategy called Value-Based" pricing, standardized pricing approach that would demonstrate to Cleveland Clinic's stakeholders that they were being transparent in their pricing strategies. They applied the pricing strategy across their 20 departments (Cleveland Clinic Transparency, 20009). The result was successful and supported their strategic initiative of value-based pricing. These are examples of both financial and strategic thinking which have resulted in strategic financial planning.

(e) step five: Integrate the financial goals with the strategic goals to ensure compatibility.

In order for health service organizations to be able to maintain excellent credit, they must maintain a long term clinical reputation which supports their credit strength. Moody Investors Services have rated the Cleveland Clinic an Aa3 rating with a positive outlook. Standards \& Poors rates it AA-minus rating. They receive these positive ratings because of Cleveland Clinic's strategic planning. In the first 6 months of 2009, their operating profit margin was $7.9 \%$ compared to a $4.6 \%$ operating margin for 2008 . Despite economic issues, the Cleveland Clinic recognized economic pressures and instituted budget constraints organizational wide in 2008. It also declined to fill nonessential positions and increased physician workloads. As a result, inpatient admissions were stable at 142,000 annually with overall hospital visits exceeding 3.6 million (Rhiggs, 2009). These results are very positive considering the fact that many individuals have lost their health insurance and have elected not to receive care which impacts healthcare organizations like the Cleveland Clinic, despite their reputation. Cleveland Clinic recognized this possibility and opted to assess their current financial status and how it was going to impact their long range plans for expansion and opted to restructure their debt.

\section{(f) step six: Identify and evaluate the organization's external environment for new opportunities.}

Successful integrated financial planning must include an assessment of their prospective market and demographics and its competitors (Grube, 2005). The Cleveland Clinic's leaders continually review their financial situation and external environment to ensure their strategic plan was based on the strengths of its organizational structure and its competitive environment. During its embryonic life cycle in 1921 to its current mature life cycle stage in 2009, they have developed strategies to maintain a dominant position in their industry. They have continued their integration of patient care and research to ensure they were offering cutting edge care. In 1995, the Heart Center was named the number one hospital nationally by the U.S. News and World Report annual survey and 
has maintained their reputation over a decade later (http://www.usnews.com).

The Cleveland Clinic was originally established in Cleveland, Ohio. As part of their strategic plan, they expanded their services to the surrounding suburbs. They currently operate 15 family health centers which also contain pharmacies and outpatient surgery centers in those areas. Recognizing the need to increase their exposure both nationally and internationally, based on marketing research, in 1988, they established a Cleveland Clinic health care facility in Weston and West Palm Beach, Florida; Toronto, Canada; and in 2012, in Abu Dhbai, United Arab Emirates. Cleveland Clinic in Florida has 150 physicians in 35 specialties. Cleveland Clinic Toronto established a facility for secondary and tertiary care and a wellness center. Their newest facility, Cleveland Clinic Abu Dhbai, scheduled to open in 2011 , will be a 360 bed multi specialty facility.

One of the most important components of a strategic plan is an external analysis to assess their direct competitors. The Cleveland Clinic's direct competitors are the Mayo Clinic in Minneapolis, Minnesota and Johns Hopkins Hospital in Baltimore, Maryland. A recent survey indicated that brand awareness of the Cleveland Clinic is substantially behind the Mayo Clinic so they need to continue focusing on their branding, although people's ability to recognize their name has increased from $20 \%$ in 1998 to $28 \%$ in 2006 . The Cleveland Clinic has recognized that Johns Hopkins usually is ranked in the top five for many of the medical specialties. Based on an internal analysis of their strengths and weaknesses, the Cleveland Clinic has recognized that fact and has focused on four niche specialties: heart disease, urology, rheumatology and gastrointestinal disorders. They rank no. 1 in heart care and number 2 in the other three specialties. Although the Cleveland Clinic provides care in over 15 specialty areas and ranks in the top 10 nationwide for most of those specialties, they have focused on becoming one of the best healthcare systems in those four areas. In 2007, the Cleveland Clinic was reorganized by combining specialties that focus on a specific organ or disease system into integrated practices called Institutes. The reorganization occurred to further create a collaborative, patient centered care. (Facts and Figures, 2008).

\section{(g) step seven: Develop financial projections based on new opportunities. Assess the risk associated with these new opportunities.}

Market intelligence provides insight to help financial planners realize maximum opportunity for any of their products with the HSO service area. By reviewing market growth rates and market share, financial projections can be maximized (Boblitz, 2006). It is also important to note the risks associated with these proposed opportunities. Risks such as any changes in operating costs, patient revenue, and productivity changes should be assessed. Also the expected net present value should be calculated to assess these new opportunities. Based on these assumptions and calculations, the optimal decision should be selected (Mclean, R., 2003). In conjunction with step four, the Cleveland Clinic continued its external analysis to asses new market opportunities.

Cleveland Clinic Innovations (CCI) was established to commercialize all inventions and related capabilities from throughout Cleveland Clinic. An 18-member Industrial Advisory Board provides oversight to CCI to link financial and management advice to support the commercialization of its technology. It maximizes the research capabilities of Cleveland Clinic with more than 200 new inventions per year. Cleveland Clinic Innovations advances commercial oriented innovation and transforms promising therapies, devices and diagnostics into products by creating spin-off companies, licensing to established companies and enabling equity partnerships. Since 2001, the Cleveland Clinic has established 25 spin off companies for the sole purpose of marketing these inventions. Despite the recession, 9 patents were issued to CCI in 2009 (http://www.clevelandclinic.org).

CCI is an excellent example of strategic financial planning. Their mission statement has focused since 1921 on patient care and providing education and research to ensure they provide quality care. By developing the CCI to foster innovation and simultaneously increase their revenues illustrates the importance of financial and long term planning.

\section{(h) step 8: Evaluate all steps and revise as needed.}

For an organization to be truly impactful, it is necessary to have perpetual strategic planning that is synchronized with the organizational budget. If the two are developed independently, any long range successful 
planning may not be successful (Gee, 2007). This is also particularly true during this economic recession. Recognizing these issues, the Cleveland Clinic opted to enter the bond market in August 2008 with a $\$ 1.1$ billion bond issue to restructure their existing debt. As part of this bond, they plan to utilize $\$ 500$ million for new construction on their main campus in Cleveland, $\mathrm{OH}$. This is an excellent example of strategic financial planning. Senior management is pursuing their strategic plan for construction of their campus while recognizing that in order to fulfill those plans, they must address the issues with their debt.

According to annual reports, their total operating revenue has increased continually. From 1998-2006, total operating revenue increased from $\$ 2$ billion to $\$ 4.4$ billion. Over $90 \%$ of their revenue comes from patient care. Their cash investments increased in 1998 from $\$ 1.2$ billion to $\$ 2.685$ billion in 2006 which indicates they are managing their funds and their debt (State of the Clinic, 2006).

\section{CONCLUSION}

A chief characteristic of successful hospitals and HSOs is the ability to develop sustainable strong financial performance over a long period of time. This type of planning is an integrated approach at all levels of the organizations to develop strategic goals in marketing, clinical outcomes, human resource management and financial performance (Gube, M, 2006).

According to Grebe (2005), solid strategic planning is essential to successful financial performance. According to rating agencies that assess healthcare organizations financial and credit status, they feel comfortable providing quality ratings to healthcare organizations that focus on the following points: (a) linking the financial and strategic plan throughout their management process; (b) market share and competitive edge; (c) measureable and successful strategy; (d) an ongoing planning process, and (e) written information to support the strategic plan. During this recession, it has become more difficult to develop accurate long term financial planning because of the increased risk of financial investments and the possibility of healthcare reform. However, the Cleveland Clinic, despite the recession, has been successful in managing their budget and their strategic plan. They have maintained positive ratings from both Moody's and Standard \& Poors which have allowed them to restructure their debt while continuing to expand their facilities and their services. They have performed strategic financial planning, increased their market share and competitive edge, measured their performance systematically, continually reviewed their planning, and maintained documentation to support their activities. As a result, they are one of the best HSO's in world.

\section{REFERENCES}

1. Boblitz, M., (July 2006). Looking out the window: Market intelligence for a view of the real world. Healthcare Financial Management, 47-53.

2. Cleveland Clinic Facts and Figures. Retrieved June, 2009 from http://www.clevelandclnic.com.

3. Cleveland Clinic transparency initiatives: CDM standardization (2009). Retrieved August 12, 2009 from http://www.deloitte.com.

4. $\quad$ http://www.clevelandclinic.org/Innovations/newventures/default.htm. Accessed August 10, 2009.

5. Gee, P., (2003). The compelling case for perpetual strategic planning. Service Line: Eight Essential Rules. Chicago: Health Service Administration Press: 62-64.

6. Grebe, M., (2005). Strategic financial planning: What every trustee needs to know about facility replacement Trustee, Nov/Dec: 24-28.

7. McLean, R., (2003). Financial management in healthcare organizations. Clifton Park, NY: 331-349.

8. $\quad$ http://my.clevelandclinic.org/about/overview/leadership.aspx

9. http://my.clevelandclinic.org/about/overview/mission history.aspx. Accessed July 31, 2009.

10. Riggs, R. Cleveland Clinic, University Hospitals get stable bond ratings from Standard \& Poors. Retrieved August 12, 2009 from http://blog.cleveland.com/medical_impact/2009/09/Cleveland_clinic_university_ho_1/.

11. Runy, L, (2005). Integrating strategic and financial planning. Retrieved July 27, 2009 from http://www.hhnmag.com.

12. State of the Clinic (2006). Retrieved July 24, 2009 from http://www.clevelandclinic.org. 
13. Sussman, J., (2007). And now, for the million-dollar question, how much can we afford to spend? The Healthcare Executive's Guide to Allocating Capital. Chicago: Health Adminisration Press: 64-70.

14. Thompson, A., Strickland, A. \& Gamble, J., (2008). Crafting and executing strategy. New York: McGraw Hill:1-17.

15. http://www.usnews.com/listings/hospitals/6410670. Accessed June 12, 2009. 


\section{NOTES}

